\title{
Alineación de la gestión estratégica del conocimiento con los modelos de gobernanza corporativa en empresas de capital abierto
}

\author{
A gestão estratégica do conhecimento sob os parâmetros dos modelos \\ de governance corporativa nas empresas com capital aberto
}

Aligning strategic Knowledge Management in open capital firms

\section{Elaine Cristina Lopes (1), Marta Lígia Pomim Valentim (2)}

(1) UNESP - Universidade Estadual Paulista Júlio de Mesquita Filho, Faculdade de Filosofia e Ciências - Campus de Marília, Rua Gabriel Santos Almeida, 295 - Cidade Universitária Marília SP Brasil, lainelopes@hotmail.com (2) Campus Universitário - Cidade Universitária - Marilia, SP - Brasil, Caixa Posta 181, valentim@marilia.unesp.br

\section{Resumen}

Se aborda la alineación de la gestión del conocimiento con las prácticas de gobernanza corporativa en empresas de capital abierto. Se destaca la importancia de dichos modelos de gestión para el desarrollo de un modelo de negocios exitoso. Se señalan los puntos en los que los modelos de gobernanza actuales presentan lagunas, y se propone una discusión sobre lo que se debe hacer. En particular, se propone la utilización de modelos de gestión del conocimiento como herramienta de apoyo para la implantación de mejores prácticas de gobernanza. A través de una investigación en una empresa de capital abierto de nivel 1 de gobernanza corporativa, fue posible identificar la relación existente entre los modelos de gestión del conocimiento alineados con los marcos de gobernanza corporativa. Para ello, se utilizó un cuestionario que alinea los elementos de gobernanza corporativa con los respectivos conceptos y modelos de gestión del conocimiento. Se constató que no existe una alineación estrecha, y se defiende, sin embargo que esa convergencia podría tener grandes ventajas para la organización estudiada.

Palabras clave: Gobernanza corporativa. Gestión del conocimiento. Mercado de capitales. Gestión estratégica.

\section{Introdução}

As recentes turbulências enfrentadas pela economia mundial e que foram fortemente sentidas no contexto empresarial e financeiro do Brasil, geraram além de perdas monetárias, a preocupação acerca de estratégias de proteção por parte dos investidores. A propósito desse contexto, seja através do alargamento do horizonte de investimentos, ou através de um melhor planejamento sobre as melhores modalidades de investimentos, o que importa para os investidores é diminuir as incertezas e preservar assim o próprio patrimônio.

\begin{abstract}
This article covers the concepts about the knowledge management practices aligned with corporate governance in the organizations opened capital, highlighting the importance attached to these types of management assistance in the conduct of business organizations. Highlights the points that still have gaps existing in governance organizations models and proposes a discussion of what remains to be done by proposing the use of knowledge management models as a tool to aid the implementation of best governance practices. Through research conducted in a company with publicly traded and listed on Level 1 of corporate governance, it was possible to identify the relationship between knowledge management models aligned with corporate governance standards. A questionary that includes elements of corporate governance in line with the concepts and models of knowledge management was applied. After finding that there is strong alignment between knowledge management and corporate governance, we present the arguments about the contributions that this convergence can bring to the organization.
\end{abstract}

Keywords: Corporate governance. Knowledge Management. Capital markets.

O preço de uma ação representa o equilíbrio entre as forças de oferta e demanda no mercado acionário. Os preços das ações são, ainda, indicadores das expectativas futuras dos agentes com relação à lucratividade e desempenho de uma determinada empresa, na medida em que os agentes se valem das informações disponíveis para a formação desses preços. O processo contínuo de acúmulo de informações por parte dos indivíduos faz com que eles não persistam em erros sistemáticos. Nesse sentido, os agentes revisam suas expectativas à medida que novas informações são incorporadas ao seu conjunto inicial (Perobelll et al., 2000, p.12).

A partir da constituição do Instituto Brasileiro de Governança Corporativa (IBGC) com a criação 
do "Código das melhores práticas de governança corporativa", e da criação pela Bolsa de Valores de São Paulo, hoje BM\&FBOVESPA, dos níveis diferenciados de governança corporativa, sendo eles o Nível 1, Nível 2 e Novo Mercado, além do incentivo de outros organismos multilaterais, as empresas passaram a se mover em busca de mecanismos que conduzem a aproximação dos interesses do poder de controle com os stakeholders (1).

As relações entre as partes envolvidas nesse processo vêm sendo objeto de estudo nos últimos anos, já que tal relação deve ser pautada por critérios de confiabilidade e transparência, especialmente no que diz respeito às informações disponibilizadas aos investidores que irão fomentar a construção de conhecimento necessário para pautar a tomada de decisão relacionada aos investimentos.

Contudo, a adesão voluntária por parte das empresas aos modelos de governança, não constituem um fator fundamental para o sucesso na gestão apoiada nos critérios considerados a base para a boa governança corporativa: transparência, equidade, prestação de contas e responsabilidade. As empresas precisam de mecanismos que auxiliem alguns pontos-chave dessas relações, fomentando efetivamente o conceito de aproximação de interesses entre as partes.

Nesse sentido, acreditamos que um fator fundamental para o desenvolvimento de estratégias adicionais de relacionamento, seja a consideração e utilização de modelos que utilizem o conhecimento gerado nas veias da organização e no contexto externo, seja quanto ao seguimento em que ela atua ou no posicionamento frente ao mercado de capitais. Uma empresa cujas estratégias possuem adicionalmente a preocupação com demais partes envolvidas, especialmente acionistas, possuem uma imensurável gama de conhecimentos a serem gerados rotineiramente através das rotinas, das ferramentas estratégicas, dos objetivos, dos produtos e, sobretudo, da transparência no que diz respeito às informações, inerente as empresas com capital aberto.

Nesse sentido, a implantação de modelos de gestão do conhecimento (GC) se constitui em um mecanismo que pode auxiliar as organizações na busca por resultados, no alcance de suas metas e na exposição de sua missão e comprometimento. $O$ estímulo de criação do conhecimento em empresas com rico teor de informações e rotinas específicas como as empresas com capital aberto, sobretudo as pertencentes a algum nível de governança corporativa, é ainda maior se comparado com outras organizações. Devido a essa especificidade, conside- ramos ser fundamental que os gestores que conhecem a importância da utilização de modelos de GC, possam aproveitar essa especificidade e riqueza de informações e relacionamentos com resultados mais efetivos.

\section{Gestão do conhecimento no contexto empresarial}

O contexto organizacional mundial vem sendo marcado fortemente por grandes mudanças ocorridas nas últimas duas décadas. No Brasil, os destaques são relacionados à abertura de mercado, às mudanças políticas e econômicas, o desenvolvimento do mercado de capitais e o rápido crescimento de tecnologias de informação e comunicação. A busca pelo desenvolvimento tecnológico, posicionamento de mercado, criação de vantagem competitiva e criação de valor para as empresas foi favorecida por essas mudanças ocorridas, ao mesmo tempo em que levou as empresas a buscarem desenvolvimento para manterem-se no mercado. O mais rápido avanço, contudo, diz respeito à convergência pela valorização da informação e dos avanços tecnológicos que permeiam esse importante ativo das empresas.

Essa transformação econômica e organizacional do mundo ocorre em meio ao mais significativo momento tecnológico da história da humanidade, estimulada por uma demanda gerada pela própria economia e pelas transformações organizacionais (Castells, 1992, p. 9).

De um modo geral, essas mudanças elevaram a necessidade das organizações de se ajustarem para suportar as exigências crescentes dos stakeholders. É nesse contexto que a gestão do conhecimento surge como um importante recurso para a criação de estratégias empresariais. As organizações começam a perceber que simplesmente conhecer seu mercado, público alvo e produto, não confere poder de competição. A vantagem competitiva ocorre de fato, quando a organização utiliza o conhecimento gerado interna e externamente aliado à gestão. A criação e implementação de ferramentas que permitam a criação, gerenciamento e o compartilhamento do conhecimento representam um grande desafio a ser enfrentado pelas empresas, contudo, configuram-se como um importante fator estratégico.

A gestão do conhecimento é um conjunto de atividades que visa trabalhar a cultura organizacional/informacional e a comunicação organizacional/informacional em ambientes organizacionais, no intuito de propiciar um ambiente positivo em relação à criação/geração, aquisição/apreensão, compartilhamento/socialização e uso/utilização de conhecimento [...] (Valentim, 2008, p.4). 
Os valores da organização alinhados ao conhecimento gerado, através de práticas e dos saberes profissionais geram a criação de valor para os stakeholders à medida que os indivíduos envolvidos nesse processo se integram de tal modo que seus conhecimentos passam a se constituir como mais um elemento da organização. Isso significa que a gestão estratégica do conhecimento propicia à organização a capacidade de incorporação dos próprios objetivos aos objetivos dos stakeholders fazendo com que haja uma renovação em suas relações, bem como ampliam os objetivos. Para Choo (2003, p. 123) as organizações percebem que o próprio desempenho depende da capacidade organizacional em dar sentido ou influenciar um determinado contexto, renovando os objetivos e reconsiderando as novas condições. A capacidade de adaptação a um ambiente dinâmico requer que a organização seja capaz de criar significado para sua existência.

Para o estabelecimento de padrões de gestão do conhecimento é necessário que a organização primeiramente procure uma compreensão acerca de qual conhecimento é relevante, de acordo com os próprios objetivos e valores. Os recursos e fatores organizacionais, aliados ao interesse que a organização possui com relação às necessidades dos stakeholders, irão definir os conhecimentos que são essenciais. Para que haja um efetivo desempenho da organização na busca por seus objetivos, é fundamental saber o que é importante conhecer, qual conhecimento irá de fato promover vantagem estratégica? Quem conhece? O que se conhece? Onde está o conhecimento?

Uma grande parcela de gestores ainda acredita que o conhecimento é mais um suporte a tomada de decisão, quando na verdade, a organização possui informações valiosas, capazes de criar conhecimento interno e externo transformando-o em um dos ativos da organização. Mas para que ocorra o entendimento quanto à importância da gestão do conhecimento, como modelagem de processos corporativos a partir do conhecimento gerado interna e externamente, é fundamental que haja uma clara compreensão da diferença entre dado, informação e conhecimento. Tal distinção é fundamental, sobretudo para organizações que utilizam informações relevantes como suporte às estratégias e relacionamento com o mercado. Dessa forma, adotamos os conceitos de Davenport e Prusak (1998, p.18), apresentados na Figura 1:

\begin{tabular}{|c|c|c|}
\hline Dados & Informação & Conhecimento \\
\hline $\begin{array}{c}\text { Simples } \\
\text { observação } \\
\text { sobre estado } \\
\text { do mundo }\end{array}$ & $\begin{array}{l}\text { Dados dotados } \\
\text { de relevância e } \\
\text { propósito }\end{array}$ & $\begin{array}{c}\text { Informação } \\
\text { valiosa da } \\
\text { mente humana. } \\
\text { Inclui reflexão, } \\
\text { síntese, } \\
\text { contexto }\end{array}$ \\
\hline $\begin{array}{l}\text { Facilmente } \\
\text { estruturado }\end{array}$ & $\begin{array}{l}\text { Requer unidade } \\
\text { de análise }\end{array}$ & $\begin{array}{c}\text { De difícil } \\
\text { estruturação }\end{array}$ \\
\hline $\begin{array}{l}\text { Facilmente } \\
\text { obtido por } \\
\text { máquinas } \\
\text { Freqüentem }\end{array}$ & $\begin{array}{l}\text { Exige } \\
\text { consenso em } \\
\text { relação ao } \\
\text { significado }\end{array}$ & $\begin{array}{l}\text { De difícil captura } \\
\text { em máquinas } \\
\text { Freqüentemente } \\
\text { tácito }\end{array}$ \\
\hline $\begin{array}{c}\text { ente } \\
\text { quantificado } \\
\text { Facilmente } \\
\text { transferível }\end{array}$ & $\begin{array}{c}\text { Exige } \\
\text { necessariament } \\
\text { e a mediação } \\
\text { humana }\end{array}$ & $\begin{array}{l}\text {-De difícil } \\
\text { transferência }\end{array}$ \\
\hline
\end{tabular}

Figura 1. Dados, informação e conhecimento. (Davenport; Prusak, 1998, p.18).

A informação gerada a partir dos fazeres organizacionais é dotada de significado, requerendo a análise e a interpretação de quem com ela interagir, o conhecimento encontra-se no contexto subjetivo de cada indivíduo, baseado numa determinada informação. Nesse sentido, Valentim (2008, p. 6) ressalta que a gestão do conhecimento alimenta a gestão da informação que por sua vez retroalimenta a gestão do conhecimento, se configurando em um ciclo em que os indivíduos são atores do processo, cujo papel é fundamental para a dinâmica ocorrer.

É importante destacarmos que a implementação de modelos de gestão do conhecimento deve ser direcionada pela intenção organizacional, ou seja, deve estar alinhada com as metas da organização. Na medida em que a organização define, de acordo com os próprios objetivos, promover a gestão do conhecimento como ferramenta estratégica, ela deverá criar a capacidade organizacional de encontrar, criar, gerir e explorar o conhecimento. Para conduzir de modo a criar vantagem através dos modelos de gestão do conhecimento a organização deve estimular o compromisso das equipes de todas as áreas, formulando uma intenção organizacional e criar possibilidades que facilitem a busca do conhecimento no contexto externo, considerando neste caso, os stakeholders. 


\section{Governança corporativa como ferramenta para criação do conhecimento organizacional}

A utilização do mercado de capitais como forma alternativa aos financiamentos tradicionais configura-se como um meio de suportar as necessidades de capital, seja para diminuição de passivos ou investimentos diversos. Na última década, vivenciamos um cenário de crescente esforço de modernização do mercado de capitais brasileiro, com reflexos significativos nos padrões de relacionamento entre poder de controle, conselho, diretoria e acionistas. Nesse sentido, a discussão sobre as melhores práticas nessas relações originou um arcabouço rico e próspero de modelos e recomendações sobre as práticas de governança corporativa que direcionam as organizações a um padrão de conduta pautado na ética, confiabilidade, transparência e comprometimento.

As discussões sobre o tema são relativamente novas, tendo seu conceito inicialmente disseminado no final da Década de 1980. No Brasil, o tema passou a ganhar destaque a partir da criação do Instituto Brasileiro de Governança Corporativa (IBGC), no final da Década de 1990. O IBGC tem contribuído para o desenvolvimento de melhores práticas de governança corporativa, apoiadas nas definições mais clássicas e que melhor esclarecem a importância do tema.

Governança Corporativa é o sistema pelo qual as organizações são dirigidas, monitoradas e incentivadas, envolvendo os relacionamentos entre proprietários, conselho de administração, diretoria e órgãos de controle. As boas práticas de governança corporativa convertem princípios em recomendações objetivas, alinhando interesses com a finalidade de preservar e otimizar o valor da organização, facilitando seu acesso ao capital e contribuindo para a sua longevidade (IBGC, 2009).

O principal objetivo da governança corporativa é a criação de mecanismos que solucionem os conflitos decorrentes da separação entre propriedade e gestão, superando o chamado "conflito de agência". Nesse sentido, grande parte das discussões e pesquisas é direcionada para a investigação da influência desses mecanismos de governança. Conforme relata Silveira et al. (2005, p.2) a maior parte dos estudos analisa as possíveis influências de mecanismos de governança, como concentração da estrutura de propriedade, estrutura do conselho de administração, estrutura de capital, política de remuneração, considerando para isso as variáveis de desempenho como indicadores contábeis de rentabilidade e métricas de valor de mercado.
Ao ampliarmos as diretrizes do tema veremos claramente a importância das empresas como fonte primária de informações para a comunidade de interesse em seus negócios. Nesse contexto, é fundamental ampliarmos o olhar as demais mudanças nos padrões de gestão decorrentes da implantação dos mecanismos internos de governança. Ainda que exista uma crescente preocupação por parte das empresas de capital aberto, pela busca de padrões que aproxime os interesses entre todos os stakeholders, há muito que ser feito. Entre os maiores desafios está a melhoria da transparência, desafios de gestão, equidade entre as partes, estrutura do conselho de administração, relacionamento com auditoria, conduta ética.

O Novo Mercado, segmento criado pela Bovespa para determinar padrões de gestão adicionais aos exigidos pela Lei das SAs, constitui um ponto de partida para a criação das melhores práticas de governança. Contudo, existem ainda pontos que demonstram que as empresas ainda precisam criar mecanismos adicionais que assegurem um real comportamento igualitário entre as partes.

Existem três razões para considerar que a governança no Brasil ainda precisa evoluir. Em primeiro lugar, o Novo Mercado não se configura como condição suficiente para a adoção de meIhores práticas. Em segundo, as empresas listadas neste segmento são consideradas uma pequena parte em meio ao cenário corporativo. Por último, pesquisas recentes demonstram que o Brasil ainda não é um país avançado no que diz respeito à governança corporativa (Silveira, 2008).

Como resultado dessas evidências, Silveira (2008, p. 3) destaca que é necessário discutir de forma prioritária, o que ele denomina de cinco dimensões chaves para o alcance das boas práticas de governança.

- Estrutura de propriedade e direito dos acionistas;

- Conselho de administração;

- Gestão e transparência;

- Auditorias e conselho fiscal; e

- Conduta e conflito de interesses.

Considerando a existência de pontos que requerem aprimoramento para que as empresas de fato alcancem um nível de exercício de boas práticas de governança, utilizamos o arcabouço científico das práticas de gestão estratégica do conhecimento empresarial, como subsídio para esse aprimoramento. Nesse sentido, destaca- 
mos que as empresas listadas em níveis de governança, ainda, apresentam posturas reservadas quando ao compartilhamento de informação e de conhecimento, que por sua vez são gerados constantemente e deveriam servir como agente de transformação nas relações internas e externas.

Observamos que grande parte dos esforços direcionados a gestão da informação no âmbito interno se referem à abordagem tecnológica e no âmbito externo se referem aos níveis de divulgação exigidos pelos modelos de governança. Quanto ao compartilhamento do conhecimento, percebemos que este se encontra de certo modo relegado, limitado aos demais padrões dos componentes integrantes do ambiente organizacional ou quando muito a uma posição secundária, condicionado ao compartilhamento de conhecimento sobre estratégias internas, não sendo utilizado como suporte às práticas de governança corporativa.

A Figura 2 apresenta a abrangência da governança corporativa, considerando os elementoschave do processo de governança e a interação existente entre os mecanismos de gestão das empresas.

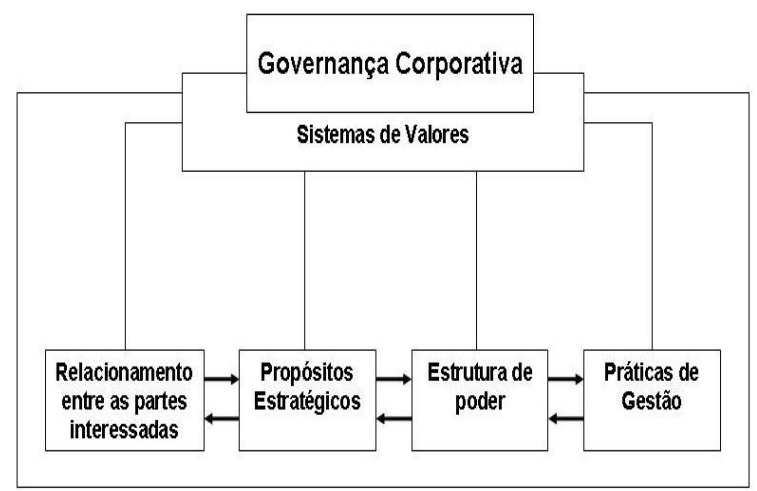

Figura 2. Elementos-chave do processo de governança corporativa (Andrade; Rosseti, 2005, p. 27).

Nessa abrangência, ocorre a aplicação dos modelos baseados nos padrões de governança, padrões adicionais, interesses da empresa e acionistas e fluxo de informações. Consideramos, além disso, que nesse contexto ocorre à criação de conhecimento que se organizado e compartilhado pode contribuir sobremaneira com as melhores práticas de governança. A Figura 3 apresenta as relações internas da organização pautadas nos modelos de governança. Essas relações convergem para a criação de conhecimento, à medida que as áreas se relacionam durante todo o fazer da empresa.
Esses padrões e obrigações são baseados no nível de governança e são implementados quando as relações entre as partes interessadas são efetivadas.

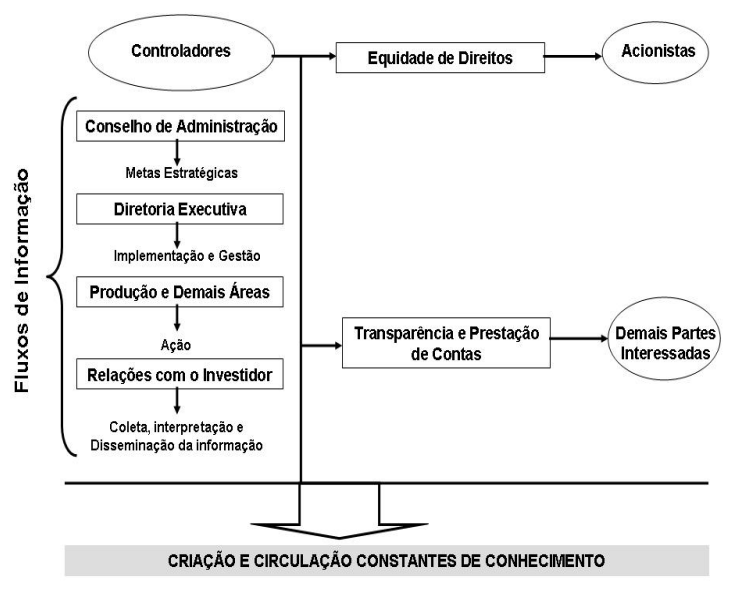

Figura 3. Criação do conhecimento como resultado dos processos organizacionais.

A partir de constatações quanto aos desafios na busca de padrões que de fato promovam a aproximação das empresas e partes interessadas, buscamos apresentar os subsídios que o estabelecimento de ferramentas de gestão e compartilhamento do conhecimento pode promover. Consideramos que tal ação não deve se restringir a procedimentos internos, mas deve alcançar os demais públicos interessados que possuem conhecimentos possíveis de contribuir e que por outro lado necessitam de ações que ofereçam uma visão clara do nível de adequação e comprometimento de cada empresa, fomentando assim a criação de conhecimento necessário para a tomada de decisão.

Dessa forma, consideramos ser importante que se crie um ambiente interno e externo, com condições para promover o processo de criação e compartilhamento de conhecimento e de transformação do conhecimento em resultados. Nesse sentido, defendemos que a criação de instrumentos de gestão do conhecimento pode auxiliar na resolução de questões que fazem parte dos desafios para que se estabeleça uma governança efetiva. Através da implantação de instrumentos de gestão e compartilhamento do conhecimento, a empresa conta com o subsídio capaz de auxiliar na solução de questões como:

- Criação de mecanismos que facilitem a participação dos acionistas em assembléias;

- Criação de comitês do conselho; 
- Avaliação de conselhos e conselheiros;

- Métodos de gestão de riscos;

- Melhorias no disclosure (2);

- Melhorias na avaliação de desempenho;

- Melhorias na comunicação interna e externa;

- Criação de mecanismos de relacionamento com analistas;

- Criação de mecanismos que aproximem a empresa com os investidores no que se referem as suas necessidades informacionais;

- Criação de métodos de gestão de auditoria interna e externa;

- Criação de mecanismos que auxiliem na criação de um código de ética, bem como sua aplicação.

A adesão por parte das organizações aos níveis diferenciados de governança corporativa são elementos essenciais para que se estabeleça $e$ se mantenha o clima de confiança necessário para que a os investidores possam tomar suas decisões de investimentos. Contudo, a organização não deve se limitar a essa iniciativa, devendo estender-se ao aperfeiçoamento desses padrões, tornando-os cada vez mais elaborados, abarcando todos os aspectos que sejam fundamentais para uma real aproximação dos interesses entre as partes. Através de iniciativas adicionais que aumentem a transparência; meIhorem a comunicação interna e externa; promovam igualdade de direitos entre outros aspectos que envolvam o relacionamento entre as partes, a organização sinaliza melhor o seu compromisso de criação de valor de longo prazo, estimulando os investidores a também adotarem essa perspectiva para seus investimentos.

\section{Metodologia}

Para a elaboração deste artigo, realizou-se uma pesquisa descritiva e exploratória, uma vez que se trata de um estudo de caso aplicado em uma empresa com a finalidade de examinar e buscar expor características do tema em questão. A pesquisa foi realizada em uma empresa do setor de papel e celulose, de capital aberto e listada no Nível 1 de governança corporativa.

Utilizou-se como meio de investigação a pesquisa bibliográfica e a aplicação de um questionário estruturado composto essencialmente por questões fechadas que foi respondido pela equipe da área de Relação com Investidores (RI) da empresa pesquisada. O questionário foi dividido em duas partes de modo a apresentar as características acerca da gestão estratégica do conhecimento sob os parâmetros da governança corporativa adotada ou não pela empresa. A primeira parte considera esses conceitos sob uma perspectiva interna e a segunda parte aborda a perspectiva externa e as relações da organização com o mercado.

O questionário constitui-se de 14 questões fechadas para as quais deveria ser escolhida apenas uma opção: Sim, Não, Não existe. Abaixo são apresentadas as questões que foram elaboradas, enviadas e respondidas pela equipe de RI.

A Parte 1 do questionário foi composta por sete questões relacionadas ao contexto interno da organização, para as quais foram utilizados os seguintes parâmetros:

1. Quanto à existência de estratégias de gestão do conhecimento alinhada às ferramentas de governança corporativa.

2. Quanto à instrução dos funcionários de todas as áreas da organização a respeito dos conceitos sobre governança corporativa.

3. Quanto ao conhecimento da alta administração sobre a consideração de que o conhecimento existente na equipe de RI é uma ferramenta estratégica de posicionamento frente ao mercado de capitais.

4. Quanto à consideração de que o desenvolvimento das ferramentas de governança corporativa gera mudança comportamental dos funcionários de todas as áreas da organização.

5. Quanto à existência de um portal, suporte ou espaço centralizado em que as experiências, conhecimentos, sugestões e opiniões podem ser compartilhadas, inclusive sobre governança corporativa, e que possa fomentar a transferência de conhecimento de uma equipe para a outra e, também, dentro da própria equipe.

6. Quanto à disseminação interna dos conceitos sobre GC com o objetivo de unir pessoas das várias unidades de negócios, a fim de construir planos estratégicos de GC alinhando as estratégias de negócio ao posicionamento no mercado de capitais.

7. Quanto à consciência da equipe de RI sobre a importância do conhecimento estratégico alinhado aos conceitos sobre governança corporativa na relação com o mercado.

A Parte 2 do questionário foi composta por sete questões relacionadas ao contexto externo da organização: 
1. Quanto à efetividade de ações da organização que estimule a criação do conhecimento dos investidores para a tomada de decisão.

2. Quanto a existência de ferramentas de coleta de informações (Ex: Customer Relationship Management (CRM)), sobre os stakeholders a fim de obter conhecimento sobre seu público alvo no mercado de capitais.

3. Quanto à utilização de Guidance (3) como ferramenta de criação do conhecimento, considerando que os analistas disseminam informações ao mercado.

4. Quanto à utilização da área de relações com investidores disponível no website como ferramenta de disseminação de conhecimento sobre governança corporativa.

5. Quanto à área de relações com os investidores disponível no website, se a organização disponibiliza espaço para que a comunidade interessada transmita seus conhecimentos, a fim de colaborar com o melhor desempenho da organização no mercado de capitais.

6. Quanto à existência da preocupação em direcionar as reuniões com analistas e investidores de modo a construir conhecimento sobre a organização e não somente divulgar informações relevantes?

7. Quanto à existência de uma estratégia definida que considere o conhecimento estratégico na definição sobre o que informar de acordo com o público interessado: sell-side (analistas de bancos e corretoras), buy-side (analistas e gestores de fundos de investimentos), outros (investidor individual, acionistas, colaboradores, instituições de mercado, mídia, estudantes).

Destacamos que a abordagem escolhida apresenta uma limitação, por se tratar de um estudo realizado com apenas uma empresa selecionada, a base do estudo é reduzida, não levando em conta, portanto, a realidade que pode vir a ser encontrada em outras empresas.

\subsection{Apresentação dos Resultados}

Apresentaremos o perfil da amostra pesquisada e a análise dos resultados com base na investigação, ressaltando interpretações e constatações consideradas relevantes. Nesse sentido, realizamos a exposição através de três tópicos que contemplam as questões levantadas e considera as respostas.

\subsubsection{Quanto à gestão do conhecimento}

A empresa revelou através do questionário, a existência de modelos de gestão do conhecimento e a importância dada ao envolvimento das equipes nos processos de construção do conhecimento. Muito embora não haja um direcionamento do questionário para a indicação de modelos haja vista a metodologia empregada para investigação, por meio de respostas que questionam a existência de ferramentas de compartilhamento da informação foi possível observar que apesar da existência de modelos de gestão do conhecimento, a empresa alegou não ter um suporte em que o conhecimento dos funcionários possa ser compartilhado, bem como qualquer outro mecanismo para a gestão do conhecimento. Nesse sentido, percebe-se uma divergência relevante entre teoria e prática, considerando que a empresa neste quesito abordado pelas questões, deixa claro sua preocupação com a interação entre os modelos de governança corporativa e a gestão do conhecimento, contudo, revela a não existência de mecanismos para tal interação. Destaca-se que a gestão do conhecimento não deve ser somente baseada no discurso, mas também pautada por critérios de condução baseados em modelos, ferramentas, processos e, sobretudo, práticas.

Embora exista a indicação por meio das respostas de certa preocupação em que os funcionários de todas as áreas da organização sejam instruídos a respeito dos conceitos sobre governança corporativa, não ocorre de fato o compartilhamento e transferência de conhecimento sobre tais mecanismos. Neste ponto, nota-se que a empresa considera relevante a construção do conhecimento sobre os modelos que norteiam a condução dos seus negócios, contudo não estabelece um ambiente que permita aos funcionários tal construção de conhecimento, bem como seu compartilhamento. Nesse mesmo contexto, o questionário revela ainda que a empresa indica não haver perspectiva ou interesse de desenvolver tal modelo de compartilhamento de conhecimento sobre governança corporativa em todos os ambientes. Novamente percebe-se a divergência entre discurso e prática, o que revela a discrepância de valores inerentes aos modelos de governança corporativa, os quais são pautados pela transparência também das relações internas. Os modelos e práticas de governança corporativa, assim como os modelos e práticas de gestão do conhecimento devem ser parte de toda a empresa e não somente recursos utilizados como atrativos ao mercado ou exclusivos do processo de gestão de algumas áreas. 
Nesse sentido, considera-se que a implantação de modelos de governança corporativa deve contemplar os modelos de gestão de conhecimento justamente para que informações relevantes sobre a importância da governança sejam compartilhadas com todos, para que desse modo haja um maior comprometimento e conseqüentemente aumento de resultados. Contudo, isso só ocorre se de fato a empresa estiver comprometida com a criação de um ambiente onde existam mecanismos e meios específicos de compartilhamento do conhecimento.

\subsubsection{Quanto ao relacionamento externo}

A empresa demonstrou através das respostas, haver o estímulo para a criação de conhecimento nos investidores para a tomada de decisão, bem como a preocupação em criar instrumentos que alinhem os objetivos e resultados da empresa com os interesses de investidores e analistas, por meio da construção do conhecimento. Contudo, as respostas indicaram que essa interação se dá através do uso de recursos tradicionais existentes entre as empresas com nível de governança, seja através da implantação de sistemas de acompanhamento de investidores no que se refere a posição acionária por exemplo. Contudo, esses exemplos tratam-se não de práticas adicionais e voluntárias de divulgação de informações com o propósito de permitir a construção do conhecimento no público de interesse, mas sim, elementos fundamentais a toda empresa com capital aberto que esteja listada em algum nível de governança.

Destaca-se que o alinhamento de interesses não é demonstrado no que se refere ao compartilhamento de informações e acesso efetivo dos acionistas à empresa, por meio de instrumentos que fomentem a construção de conhecimento a fim de colaborar com o melhor desempenho da organização no mercado de capitais bem como alcançar tal alinhamento. Nesse sentido, novamente percebe-se uma diferença entre discurso e prática, o que revela uma preocupação limitada, que na realidade diz respeito ao que se tem como básico entre as empresas de capital aberto. Contudo, defende-se que a criação de mecanismos que de fato aproximem os interesses do público com a realidade da empresa é o que de fato pode ser considerado como insumo para a construção do conhecimento. Entre as principais falhas existentes nas relações entre empresa e seus stakeholders está à falta de comunicação eficiente, haja vista que as empresas oferecem mecanismos de acesso a informações que muitas vezes não são suficientes, ou então, não estão próximos da realidade de todos os interessados em tais informações.
Considera-se que divulgar informações relevantes é uma ação obrigatória e não voluntária. $O$ que de fato pode revelar o comprometimento da empresa são os meios através dos quais a empresa disponibiliza tais informações. Neste caso analisado, a empresa apresenta um comportamento típico de várias empresas com modelos de governança corporativa, qual seja o de divulgar dentro do limite legal, através das mídias legalmente impostas, não se comprometendo com a criação de mecanismos que contribuam com a construção do conhecimento a partir das informações divulgadas.

\subsubsection{Convergências entre governança corpora- tiva e gestão do conhecimento}

Observamos através da pesquisa, que a empresa compreende a importância da implantação de modelos de gestão do conhecimento, bem como considera a importância do comportamento organizacional frente às mudanças e interesses da empresa. Quanto à governança corporativa, a empresa se preocupa em oferecer uma estrutura de relacionamento com investidores e considera a importância do conhecimento gerado nesses indivíduos.

Contudo, quando as questões partiam para assuntos relativos à prática, não se observou uma convergência real entre os elementos existentes nos modelos de governança corporativa e os conceitos sobre gestão do conhecimento. Esse dado pode ser observado quando do questionamento sobre a visão da empresa quanto à importância da gestão do conhecimento aliada à condução dos modelos de governança corporativa, tendo-se como retorno sempre respostas afirmativas Do mesmo modo quando questionada sobre a preocupação, tanto com o público interno quanto com o público externo, de que estes possuam conhecimento sobre governança corporativa, as respostas sempre foram afirmativas. Entretanto, a seção que tratava sobre os mecanismos e meios que possam de fato fomentar a construção do conhecimento apresentaram questões negativas, revelando que muito embora a empresa tenha consciência da importância e aponte sua preocupação com tais critérios, ela não oferece e nem apresenta perspectivas de oferecer os meios através dos quais tais critérios sejam de fato implementados e praticados.

Nesse sentido, destaca-se que a pesquisa revela a não existência de uma real interação entre os modelos de gestão do conhecimento e os modelos de governança corporativa na prática. 


\section{Conclusões}

Este artigo buscou apresentar a importância do desenvolvimento das melhores práticas de governança corporativa que de fato sejam alinhadas aos interesses de todas as partes envolvidas na organização. Desse modo, apresentouse que tal alinhamento pode ser alcançado mediante a convergência das práticas de governança com os conceitos e modelos de gestão do conhecimento. Nesse sentido, destaca-se que a adesão voluntária aos níveis diferenciados de governança corporativa, não configuram como fator fundamental para o sucesso nessas relações e que por si só não propiciam a construção do conhecimento interno e externo sobre tais níveis e os benefícios que estes podem oferecer a todos os stakeholders. Isso porque foi possível observar que muitas lacunas identificadas se devem à inexistência de ações que vão além do exigidos nos padrões de governança.

Durante a análise das questões levantadas, percebeu-se uma disparidade entre o que a empresa entende como importante no que diz respeito à gestão do conhecimento e o que ela de fato pratica. Através de questões sobre o posicionamento da empresa quanto à preocupação com a construção do conhecimento interno e externo, esta se posicionou como facilitadora, contudo, ao adentrarmos na seção pertinente à prática, a pesquisa revelou que a empresa não possui mecanismos que favoreçam a construção do conhecimento alinhada aos modelos de governança corporativa. Tal realidade pode ser percebida quando da análise quanto ao desinteresse da empresa de se elevar os mecanismos que permitam a construção do conhecimento.

Destacamos que muito embora a empresa tenha afirmado possuir ferramentas de gestão do conhecimento, a pesquisa revelou que não ocorre o alinhamento desses modelos com os padrões e interesses existentes nos modelos de governança corporativa. A realidade percebida nessa pesquisa realizada em uma única empresa, ainda que o caráter não nos permita extrapolar para a totalidade das empresas listadas nos níveis de governança dado o método escoIhido, nos revela apenas um exemplo do que muitos pesquisadores e especialistas brasileiros já tratam nos últimos anos. Essas inúmeras pesquisas vêm revelando que as empresas de um modo geral preocupam-se com os limites legais, não oferecendo mecanismos adicionais e voluntários de acesso à informação com critérios que de fato promovam a construção do conhecimento.
Considera-se que os modelos de gestão do conhecimento, por serem instrumentos que conduzem as organizações na busca por resultados através do conhecimento gerado interna e externamente, podem fornecer subsídios para a elevação do padrão dos modelos e práticas de governança corporativa, isso porque, ainda existem pontos que merecem maior rigor nos padrões de governança, especialmente os que dizem respeito à aproximação dos interesses entre organizações e stakeholders por meio da disseminação de informações.

Destaca-se que esse trabalho teve apenas o objetivo de realizar uma análise inicial acerca dessa temática, deixando espaço para outros estudos sobre as possibilidades de alinhamento entre os dois temas. Isso porque a convergência entre governança corporativa e gestão do conhecimento pode tornar as empresas e stakeholders mais próximos dos reais objetivos das práticas de governança corporativa.

\section{Notas}

(1) Stakeholders é um termo inglês que designa uma pessoa, grupo ou entidade que possuem interesses nas ações e no desempenho de uma organização.

(2) Disclosure é um termo inglês utilizado para designar a transparência na divulgação das informações relevantes das empresas.

(3) Guidance é um termo inglês que se refere a um relatório emitido ao mercado pelas empresas contendo uma estimativa de resultados.

\section{Referencias}

Castells, M. A. (1992). A economia informacional, a nova divisão internacional do trabalho e o projeto socialista. $\mathrm{CRH}$, Salvador, 1992. 5-34

Choo, C. W. (2003). A organização do conhecimento: como as organizações usam a informação para criar significado, construir conhecimento e tomar decisões. 2. ed. São Paulo: Senac, 2003.

Davenport, T. H.; Prusak, L. (1998). Ecologia da informação: por que só a tecnologia não basta para o sucesso na era da informação. São Paulo: Futura, 1998.

IBGC - Instituto Brasileiro de Governança Corporativa (2008). Código das melhores práticas de governança corporativa. <http://www.ibgc.org.br/ibConteudo.asp? IDArea $=864 \& \mid D p=3>$. $(2010-06-08)$.

Perobelli, F. F. C; Perobelli, F. S; Arbex, M. A. (2000). Expectativas racionais e eficiência informacional: análise do mercado acionário brasileiro no período 1997-1999. RAC. 4:2 (2000) 7-27.

Silveira, A. M. (2008). Desafios da governança: ir além do Novo Mercado. Valor Econômico, São Paulo, p.D2, ago. 2008.

Valentim, M. L. P. (2008). Informação e conhecimento em organizações complexas. In: Valentim, M. L. P. (Org.). Gestão da informação e do conhecimento no âmbito da Ciência da Informação. São Paulo: Polis: Cultura Acadêmica, 2008. p.11-25; 272p.

Valentim, M. L. P. (2008). Gestão da informação e gestão do conhecimento em ambientes organizacionais: conceitos 
e compreensões. // Tendências da Pesquisa Brasileira em Ciência da Informação, Brasília. 1:1 (2008) 1-16.

Recibido: 20-04-2010. Revisado: 01-07-2010.

Aceptado: 06-07-2010. 